\title{
Open innovation in SMEs: \\ Exploring inter-organizational relationships in an ecosystem
}

\author{
Agnieszka Radziwon \\ Aarhus University, \\ agra@btech.au.dk \\ Marcel Bogers \\ University of Copenhagen, \\ marcel@ifro.ku.dk
}

\begin{abstract}
Small- and medium-sized enterprises (SMEs) face the inherent tension of depending on external partners to complement their internal innovation activities while having limited resources to manage such open innovation processes. Given the importance of collaborative efforts between multiple stakeholders, we address the open innovation challenges from the SME perspective at the business-ecosystem level. We present an inductive case study of a particular regional ecosystem and focus on the inter-organizational collaboration between SMEs and other stakeholders in the ecosystem. With this focus, we explore how SMEs perceive, organize, and manage open innovation through strong collaborative ties with other ecosystem members. We identify a particular set of challenges for the SMEs due to the misalignment between their business model and that of their ecosystem. Specific findings include the link between innovation type expressed by diverging understandings of the notion of innovation across the ecosystem and the innovation form (here, open innovation), which should be organized and managed on multiple levels of analysis (SME, inter-organizational, and ecosystem). These findings highlight specific attention points for managing and developing open innovation in a regional business ecosystem, and they contribute both to the businessecosystem literature as well as open innovation literature.
\end{abstract}

\section{Keywords:}

Open innovation, Ecosystem, SMEs, Multilevel perspective

\section{ACKNOWLEDGEMENTS}

A previous version of this paper was presented at the 1st Annual World Open Innovation Conference, Napa, CA (December 2014) as well as DRUID Conference, Copenhagen (June 2016) and the Academy of Management Meeting, Atlanta, GA (August 2017). We would like to thank Industriens Fond for their financial support.

Complete reference: Radziwon, A., \& Bogers, M. 2018. Open innovation in SMEs:

Exploring inter-organizational relationships in an ecosystem. Technological Forecasting \& Social Change, forthcoming 


\section{Introduction}

Open innovation, which describes knowledge inflows and outflows for improved innovation performance, is widely acknowledged as an important innovation management practice (Chesbrough, 2003; Chesbrough et al., 2014; Dahlander and Gann, 2010). Many aspects of this field have yet to be explored, however, and our understanding of the open innovation concept therefore remains underdeveloped (Bogers et al., 2017; West and Bogers, 2014, 2017). For example, one area receiving increasing interest in recent years is the role of open innovation in small- and medium-sized enterprises (SMEs) (Brunswicker and Van de Vrande, 2014; Vanhaverbeke, 2017; Vanhaverbeke et al., 2018). SMEs do not benefit from open innovation in the same way as large firms (Usman et al., 2018; Vanhaverbeke, 2017), and therefore we cannot easily benchmark the successful open innovation examples from multinational corporations to small firms. A more detailed understanding of the exact conditions under which SMEs can successfully implement an open approach to innovation therefore remains lacking. This is particularly true when considering the relatively few studies focused on open innovation in business ecosystems (Radziwon et al., 2017; Ritala et al., 2013; Van Der Borgh et al., 2012), thus amplifying the lack of understanding of how SMEs can manage open innovation in such ecosystems.

In light of how new opportunities are generated for additional value creation much more often in open innovation than when following closed innovation principles, this research aims at increasing our understanding of the inter-organizational collaboration between SMEs and other regional business ecosystem stakeholders through the lends of open innovation. That is why this paper explores how SMEs (embedded within a larger ecosystem) perceive, organize, and manage open innovation through strong collaborative ties with other ecosystem members. Our investigation is based on an in-depth case analysis (Eisenhardt, 1989; Glaser and Strauss, 1967) of seven manufacturing SMEs that are part of the same regional business ecosystem. 
The research focuses on the inter-organizational collaboration taking place in an ecosystem in which the various SMEs are embedded, thereby addressing their role in the larger ecosystem of complementary partners (Adner and Kapoor, 2010; Moore, 1993; Van Der Borgh et al., 2012).

This research is based on the open innovation framework to explore knowledge inflows and outflows that support improvements in the innovation performance of SMEs (Chesbrough, 2003; Dahlander and Gann, 2010; Gassmann, 2006). Within the broader framework of open innovation, however, much attention has been given to large firms, with only limited attention to start-ups and SMEs (Bogers et al., 2017; Brunswicker and Van de Vrande, 2014; Eftekhari and Bogers, 2015; Van de Vrande et al., 2009). There are still relatively few studies that analyze business ecosystems from the SME perspective, especially in the context of open innovation (Radziwon and Bogers, 2018; Radziwon et al., 2017). Thus, we would like to contribute both to the business ecosystems (Scaringella and Radziwon, 2018) and open innovation literature (Bogers et al., 2017) by developing a better understanding of the potential contribution of SMEs to ecosystem development through the application of open innovation practices.

The paper begins by providing the theoretical background of the study, including the definition of open innovation, which is the context of the study as well as business ecosystem as a unit of analysis. Next, we describe the applied research strategy, including theoretical sample justification, data gathering protocols, and the analytical techniques used to develop the findings. Subsequently, the case study evidence is presented and discussed. We conclude with a summary of the key findings and the implications for open innovation management in SMEs in the context of the regional ecosystem, as well as their limitations and possible future research extensions. 


\section{Theoretical background}

\subsection{Open innovation: State of the art in large firms and SMEs}

Open innovation has initially been defined as "the use of purposive inflows and outflows of knowledge to accelerate internal innovation, and expand the markets for external use of innovation, respectively” (Chesbrough, 2006, p. 2). This definition has been further developed and clarified to "a distributed innovation process based on purposefully managed knowledge flows across organizational boundaries” (Chesbrough and Bogers, 2014 p. 17). Contemporary innovation model has shifted from closed “in-house” R\&D to combining both internal and external sources of ideas, technologies, and other kinds of information that could help companies to innovate. Most of the attention in the open innovation literature has been paid to the inbound process of knowledge inflows to accelerate internal innovation, with less attention to the outbound process of knowledge outflows (West and Bogers, 2014).

Initially, open innovation research provided evidence of various positive influences of its adoption in large multinational companies, such as IBM, Lucent, and Intel (Chesbrough 2003), DSM (Kirschbaum 2005), or P\&G (Dodgson et al., 2006; Huston and Sakkab, 2006). Further studies investigated the potential for the implementation of open innovation practices, also in SMEs (see, e.g., Bianchi et al., 2010; Lee et al., 2010; Van de Vrande et al., 2009). Building on the increasing interest in open innovation in both large companies and SMEs, Spithoven et al. (2013) focus on the effects of open innovation practices in SMEs relative to large companies. This research shows that open innovation activities are performed more intensively in SMEs. SMEs also depend more on open innovation than big companies because their practices impact their revenues much more significantly. In terms of search strategies, which generate an innovative turnover, SMEs benefit from them much less than large companies. Moreover, the researchers point out collaboration between SMEs and other innovation partners as a means to foster the introduction of new offerings. 
More recent studies collected by Vanhaverbeke et al. (2018) explore, among other things: SME collaboration with external designers (Dell'Era, et al., 2018) and crowd-sourcing platforms (Anderson et al., 2018), how open innovation adoption supports frugal development (Hossain 2018), how SMEs are involved in crowdfunding (Giudici and Rossi-Lamastra, 2018), and the characteristics of key individuals in SMEs - entrepreneurial leaders who support the open innovation adoption process (Ahn et al., 2018). These studies shed light on how open innovation is managed and implemented, thereby offering further insight into the peculiarities of the open innovation practices of SMEs compared to open innovation management in large multinational companies. The edited volume by Vanhaverbeke et al. (2018) is a natural follow up and extension of Vanhaverbeke (2017), which indicates that despite some commonalities, the knowledge we possess about open innovation practices in large firms is not easily transferable to SMEs. Due to substantial differences between these large and small firms, the latter require a special open innovation framework that will help them succeed, not only in open innovation implementation but in a longer perspective in terms of keeping up with increasing market and customer demands. Some of the key differences mentioned by Vanhaverbeke (2017) include a portfolio of innovation projects, typically in large players not necessarily in small firms, or innovation management as a function and role fulfilled by a separate manager in a large firm and by an entrepreneur or company founder in a small firm. This research identifies the opportunities for spreading the risk inherent in innovation projects and sharing intellectual property between project partners, thus developing products beyond the current capabilities of a single firm. Better understanding of open innovation processes in SMEs therefore remains necessary, especially in order to enhance the understanding of the drivers and challenges for establishing successful partnerships (Brunswicker and Van de Vrande 2014). Furthermore, the few studies focusing on open innovation in business 
ecosystems grant limited attention to SMEs and their potential contribution (Pop et al., 2018; Radziwon and Bogers, 2018; Radziwon et al., 2017; Van Der Borgh et al., 2012).

Even though an open approach to obtaining, integrating, and commercializing external sources of knowledge (Laursen and Salter, 2006; West and Bogers, 2014) may largely stimulate successful innovation, finding new ways of organizing innovation activities in the larger context than the current operational scale may be very challenging for SMEs (Van de Vrande et al., 2009). Scholars might even discourage SMEs from implementing open innovation paradigms in some cases. After theorizing about innovation in clusters of small, high-tech firms, Oakey (2013) concludes that the potential for greater openness in industrial research and development is overstated due to the lack of proper appropriation mechanisms (e.g., related to intellectual property), and he highlights the merits of closed innovation.

Emphasizing external sources of knowledge, Laursen and Salter (2006, p. 146) point out that "searching widely and deeply across a variety of search channels can provide ideas and resources that help firms gain and exploit innovative opportunities.” There is also increasing interest in the coupled open innovation process that combines knowledge inflows and outflows (Enkel et al., 2009). Such processes tap into a larger literature on interorganizational collaboration, which has emphasized the general importance of knowledge transfer for innovation and the specific relevance of inputs such as time, labor, and other resources. Along these lines, studies have shown that inter-organizational collaboration can be an important driver for innovation performance (Powell et al., 1996). Accordingly, firms embedded in networks can leverage their external environment to achieve better innovative output (Shan et al., 1994). As most of the mentioned studies have focused on the company level of analysis, researching other units of analysis could provide a complete picture of the relevant processes and contingencies (West et al., 2014, 2006). One such level of analysis relating to the constellation of innovation actors is the business ecosystem (Adner and Kapoor, 
2010; Rohrbeck et al., 2009; Van Der Borgh et al., 2012). Since the context dependency of open innovation remains little understood, more research on open innovation in the whole business ecosystem is required (Bogers et al., 2017; Chesbrough and Bogers, 2014).

\subsection{Knowledge management in ecosystems and regional innovation systems}

Various ecosystem concepts were coined in the early 1990s and have since been further developed. Different types of ecosystems appear to have originated from the "business ecosystem” proposed by Moore (1993), who in turn built on territorial innovation models (Moulaert and Sekia, 2003; Scaringella and Radziwon, 2018). As both ecosystems and regional innovation systems (RIS) placed strong emphasis on knowledge, especially its purposefully managed inflows and outflows, scholars tend to use the term ecosystem interchangeably with clusters or regional innovation systems. The territorial aspects related to geographical proximity, is definitely one of the commonalities between RIS and ecosystems; however, strong interdependencies and the co-evolution observed between ecosystem members lean towards advantages related to cognitive proximity going beyond typical RIS relationships. Moreover, the key source of knowledge spillovers with both regional clusters and RIS are research institutes and universities (Asheim and Coenen, 2005), which are also important sources of knowledge in ecosystems. The ecosystem perspective nevertheless extends the potential knowledge-sourcing landscape and receives all sources of inbound, outbound, and coupled modes of purposive knowledge inflows and outflows (West and Bogers, 2014). Last but not least, the ecosystem perspective consists of many informal structures and contractual agreements that are made possible due to high trust and relatively low transaction costs (Radziwon 2017), which as noninstitutionalized structures are not widely acknowledged by RIS. According to Oh et al. (2016), ecosystems are often perceived as (bottom-up) organically grown structures; this stands in contrast to critical-mass industrial clusters, which tend to be formally structured, often formed by policymakers top-down. 


\subsection{Open innovation at the level of business ecosystems}

While open innovation has received increased attention in innovation management research, this has mostly been at the company level, with a lack of research on other levels (West et al., 2006). One such level of analysis relating to the constellation of innovation actors is the business ecosystem (Adner and Kapoor, 2010; Van Der Borgh et al., 2012; Rohrbeck et al., 2009). One of the first conceptions of a business ecosystem was developed by Moore (1993), who emphasized the cooperation and competition that occurs simultaneously between companies that coevolve new capabilities leading to new innovations. In his view, "a business ecosystem, like its biological counterpart, gradually moves from a random collection of elements to a more structured community” (Moore 1993, p.76). He also distinguishes between different stages of the ecosystem development, where different challenges related to collaboration or/and competition may emerge.

Different views and related concepts have emerged in the context of business ecosystems. Some argue that an ecosystem is much bigger and richer than a firm's immediate customer-supplier network. At the same time, the perceptions of its dimensions differ depending on perspective (e.g., a single SME initiative or a collection of multiple large enterprises) (Moore 1996). The indicators of an ecosystem might refer to a network of relationships with future potential regardless of the size of the system (Moore 1996). Some scholars refer to an ecosystem as a "community” (Iansiti and Levien, 2004; Moore, 1996), although that concept has been ill-defined and approached in various different ways, not least in the context of open innovation (West and Lakhani, 2008).

Business ecosystems can be characterized as consisting of a variety of types of stakeholders, including suppliers, customers, competitors, universities, and other complementors, all of whom play a different role relative to the other actors in the valuecreation process (Adner and Kapoor, 2010; Afuah, 2000; Eisenhardt and Galunic, 2000; Iansiti and Levien, 2004; Moore, 1996; Van Der Borgh et al., 2012; West and Bogers, 2014). In the 
words of Iansiti and Levien (2004, p.5), these stakeholders are "loosely interconnected participants that depend on one another for their effectiveness and survival." "Membership" in this ecosystem therefore requires a certain level of inter-dependency between participants. In the context of open innovation, knowledge becomes an important medium of interaction between business ecosystem members. All of the key elements of the ecosystem that we consider to be prerequisites for the region or sample selection (orchestration and proximity) and those that we empirically test and analyze (co-evolution and interdependencies) are outlined in Table 1.

Insert Table 1 about here

\section{Research design}

In order to thoroughly examine the phenomenon of our theoretical interest in its reallife context (SMEs embedded in a regional business ecosystem), we employed case study methodology (Yin 2003). A case study approach helped us to explore inter-organizational relationships as well as to identify patterns that allowed us to address research gaps and pursue a replication logic (Eisenhardt, 1989; Eisenhardt and Graebner, 2007) (applied within case study generalization boundaries).

The theoretical sample was chosen based on 1) ecosystem embeddedness (orchestration and geographical proximity) (see Table 1), 2) company size, and 3) active participation. In order to research inter-organizational relationships within the ecosystem context, the investigated units must be part of an ecosystem. As briefly discussed in the theoretical background, two main sampling prerequisites are the presence of a large firm that constitutes a key customer, supplier, or partner in the ecosystem (its exact role and involvement is not in- 
depth analyzed and discussed in this paper); and the spatial proximity between the selected companies (the distance between the central city in the region and a company should be less than $25 \mathrm{~km}$ ) (Freel 2003; Sternberg 1999). Size-wise, the main interest of this research falls into the highly understudied group in "the small end" of manufacturing SMEs with fewer than 100 employees. These are typically low- to medium-tech companies. Last but not least, active participation, understood as involvement in various activities with other companies and institutions, should ensure some exposure to potential knowledge-exchange processes. We have focused on companies that are active in different types of local organizations (e.g., different clusters) and those that have documented a history of collaboration (related both to core and noncore activities) with other local companies or public institutions (e.g., the university). The company database was developed as a joint effort of involved researchers, university officers responsible for industry collaborations, and representatives of local Danish clusters. Of the shortlisted companies, 12 firms from the local business ecosystem in Southern Denmark accepted our research invitation.

\subsection{Data collection}

In order to ensure research validity through data triangulation, we employed multiple data sources. These included semi-structured interviews (as primary data) with CEOs, managing directors, and company co-owners who could offer real-time accounts and retrospective views on the phenomenon of our theoretical interest (Gioia et al., 2012). The secondary data covered field observations (from the manufacturing facilities of the companies we visited), media documentation, publicly available registers, company websites, and documents provided by the interviewees. To strengthen the research reliability, all of the interviews were conducted face-to-face, recorded, transcribed, and sent to the industrial participants for their comments and final approval. We conducted two rounds of interviews that were based on previously developed and jointly approved interview guidelines. 
Investigator triangulation was applied to avoid potential biases in the data collection and subsequent analysis. This was executed in the presence of three researchers in each interview. One researcher participated in all of the interviews, two colleagues were assigned to the first or second interview rounds with a company, and each company had its own assigned researcher. The latter person would focus only on one company without participating in interviews with other companies. The transcription process followed the previously developed protocol. Each transcript was reviewed by two other researchers to ensure the proper understanding of the informants.

Twenty-three on-site interviews were conducted, lasting between 60-120 minutes. As we reached data saturation relatively quickly, we decided to focus on the theoretical sample of seven Danish manufacturing SMEs that would offer the broadest insights and a greater diversity of perspectives. The remaining SME cases did not exhibit any significant pattern deviations. As the initial sample consisted of two large companies (including the ecosystem orchestrator), we were able to ensure a good understanding of various perspectives and to clarify potential concerns. Table 2 presents an overview of the selected cases.

Insert Table 2 about here

\subsection{Data analysis}

The data analysis related to an inductive qualitative study with a grounded theory approach, where researchers tried to extract, identify, and develop themes that capture the innovation phenomenon in SMEs (Dougherty 2002). The inductive analysis aimed at identifying themes from within the embedded cases and comparing these finding across cases. The grounded theory approach was reflected in the construction of categories of findings by developing categories of information (open coding), interconnecting the categories (selective 
coding), and building a story that connects the categories (axial coding), upon which the final findings are based (Corbin and Strauss, 1990; Dougherty, 2002). The construction of categories can therefore be seen as an iterative process that establishes common meaning across multiple observations (Locke 2001). In order to develop a comprehensive understanding of the phenomenon, the analysis involved multiple researchers independently analyzing the coding of each single company case together with cross-case analysis (first without and then contracted with independent, single-case coding).

\section{Findings and discussion}

At the beginning of the research and data collection process, we considered the selected sample of SMEs as part of a particular cluster. In the course of the data collection process, however, we realized that membership in a particular cluster is just one of the initiatives in which these companies are involved. Each interview revealed new connections between the companies, which were not necessarily related to mechatronics, which was otherwise the theme of the cluster. The Company F CEO framed this rather well:

If we have an organization and the chairman and if we pay to be a member or we don't, the Mechatronics Cluster is there anyway. It doesn't need an organization to be there - it's there; and this is a strength for all the other initiatives, because we don't need to be called the Mechatronics Cluster to be one. We're there. The companies are there. It's a cluster - real life.

This way of thinking about the ecosystem indicates the presence of self-propelled mechanisms that are an integral part of the ecosystem co-evolution process (see Table 1).

The companies from the region somehow stuck to the idea of the mechatronic cluster due to it always having been there. However, we realized that the "organization" that we have approached and talked about resembles more an ecosystem (Adner and Kapoor, 2010; Iansiti 
and Levien, 2004; Van Der Borgh et al., 2012). One aspect is that it is not only connected to a theme but that it resembles a biological ecosystem (Moore, 1996) given its particular geographical location (see Table 1 and Figure 1).

Insert Figure 1 about here

Due to a variety of stakeholders, it is much bigger and richer than a firm's immediate customer-supplier network (Adner and Kapoor, 2010; Afuah, 2000; Eisenhardt and Galunic, 2000; Iansiti and Levien, 2004; Moore, 1996; Van Der Borgh et al., 2012; West and Bogers, 2014). Moreover, it includes cooperation and competition activities (Moore, 1993). There is also a certain level of inter-dependency between participants (see Figure 1). The enterprises constituting our sample co-evolve while co-existing in the similar region.

In the process of making sense of the collected evidence, we found considerable support in Mitra (2017), who distinguishes the type of innovation (e.g., product, process, incremental, radical), which explains the constituent elements on innovation and form of innovation (e.g., open innovation, frugal innovation), which exhibit the shape of specific innovation type in a specific context. In his view, the innovation process links these two together. We also adopt Mitra's (2017) understanding of organizing as a form of division of labor and organization of efforts. Based on observations and analysis of the acquired data, we were able to distinguish between organizational and inter-organizational level factors influencing the inter-firm relationship-building and collaboration conditions. This section further discusses the connections between various levels of analysis together with the link between these analytical levels and how open innovation practices might stimulate the further development of the ecosystem. 


\subsection{Perceiving and understanding of open innovation throughout the ecosystem}

Adner (2006) addresses the topic of interdependencies between innovation partners. The co-evolution of the partners - and thus the ecosystem - therefore depends on innovation. In order to innovate in an ecosystem, however, one is dependent on the innovation activities of the various partners. However, any misalignments or divergence in terms of how innovation is perceived might pose additional challenges to the ecosystem development; especially considering how various types of collaborative agreements initiated within the innovation ecosystems for many firms have become an important element in growth strategies (Adner 2006).

In this particular innovation ecosystem, we observed limits regarding the understanding of innovation throughout the ecosystem. While the SMEs in this ecosystem are highly dependent on one another, the empirical evidence also reveals that the perception of what constitutes innovation differs substantially across this group. This difference appears to be strongest for the SMEs that are active in different business types. That the SMEs view things differently is hardly surprising, especially in light of the broader context of the misalignment of the perception of what constitutes innovation between SMEs and other innovation stakeholders like academics and policymakers reported by Massa and Testa (2008).

The most significant differences can be observed in companies selling their products on regulation-driven markets (Table 3, Company D1). Some of the governmental regulations that a company is exposed to can be perceived as opportunities that can otherwise become a threat. Knowing future directives makes it possible to gain a competitive advantage based on competencies and R\&D performance. If anything unexpected happens, however, and the new product could be too radical to comply with set standards, it will be automatically rejected from 
the bid. Lundvall et al. (2002) therefore suggest that policymakers change the legal framework in a way that would weaken the position of imitators and strengthen the position of radical innovators.

Insert Table 3 about here

Some SMEs perceive customization as the process of delivering a novel solution (usually both to the company and the market), which in this case could be perceived as product innovation (Table 3 Company A (1\&2), B1, C1, E1). In the context of open innovation, there is also a strong link to customers and their expectations, which a company tries to fulfill by creating a value-added product (Table 3 Company C2, E2). Most of the SMEs in the ecosystem underline customization as their main strength (Table 3 Company B1, C1, E1), which is in line with the literature that regards them for their operational expertise and customer knowledge (Massa and Testa, 2008).

Moreover, customization (or innovation through customization) is perceived as userdriven innovation (Table 4 Company A3) resulting from the involvement of users in the development and production process, which is perceived by SMEs as one of their strengths. The role of user innovation or involvement creates the need to appropriate process to transfer the users' sticky knowledge to the SME, possibly through the development of (SME-)specific toolkits (Bogers et al., 2010; Franke and Von Hippel, 2003; Von Hippel, 1994). Employee involvement is important in innovation as well as the decision-making process. This is mirrored in the company's strong focus on recruitment to provide new knowledge and skills (Table 4 Company E4), which could also be a major stimulus for establishing collaboration (Rothwell and Dodgson, 1991). 
The literature reports that the level of flexibility together with an ability to adjust the product according to customer needs draws a significant distinction between SMEs and large companies - to the advantage of the former (Narula 2004). However, some of the ecosystem members found a way to maintain this flexibility while also combining it with scalability through mass-customization platforms (Table 4 Company E6, F2). Interestingly, the same companies claim that they do not have any direct competitors due to the niche that they found.

Another understanding of open innovation relates to the knowledge that current or potential customers might provide to the product development process (Massa and Testa, 2008). One of the threats in the traditional (closed) innovation model used to be divergence between customer needs and product features. Not all of the interviewed companies would agree that customer involvement in the product development process would produce satisfactory results. According to the managing director of Company E(2) (Table 3), listening to the customers is not always enough; the problem may lie elsewhere, as the user points out. What is more, in his view the company has to have its own contribution to the solution.

Insert Table 4 about here

Differences in the perception of value creation and capture might be based on differences between the ecosystem participants' business models, which are defined as the logic of how companies create and capture value through their activities (Zott et al., 2011). This might explain why, for some firms, it is not always good to grab after the newest technology - it is sometimes better to have something reliable that will comply with various regulations and directives and what customers will be able to understand. It could also relate to the existence of various levels of open innovation (Gupta et al., 2007; West et al., 2006, 
2014). Moreover, based on the divergent perception of innovation, we derive two organizational factors that could influence inter-organizational collaboration on innovation:

1) Regulations, the market, customers, and/or users drive the firm.

2) Product and/or technology complexity.

\subsection{Organizing inter-organizational knowledge flows in the ecosystem}

We have also explored how to organize for open innovation. A very special perception of "collaborators" might play an important role in the open innovation ecosystem. Our empirical evidence points out that even if most of our interviewees are suppliers to some large enterprises (see Figure 1) or have some sort of partnership, they do not consider themselves equals. This is in line with Narula (2004, p.159), who points out that SMEs "have relatively little to offer.” Our empirical evidence from interviews with Company A2 and G3 (Table 4) illustrate this situation very well. Large and small companies seem to represent different interest groups, and they place different values on the joint project than SMEs do and might therefore not treat one another as partners (Rothwell and Dodgson, 1991).

Due to their size and financial capabilities, SMEs are willing to cooperate not only with complementors but even with competitors (Ritala and Hurmelinna-Laukkanen, 2009) (Table 4 Company A4, B3, D3); both solutions are rooted in the increasing need to acquire multiple competencies (Granstrand et al., 1997; Rothwell and Dodgson, 1991). In their world, we are not necessarily talking about a zero-sum game in which one must lose for another to win; if none of the suppliers is able to handle the order, it might be better for them to collaborate and share the revenue than to fight and be left with nothing Even competitors can therefore potentially provide additional resources, which can be mutually beneficial (Kogut et al., 1992; Lee et al., 2010). This is nicely exemplified by Company A4, which argues that collaboration with competitors is not easy, but durable (Table 4). Additionally, for very innovative companies, the fact that competitors exist could prove that the product/service exists (Table 4 
Company F1). Both financial capabilities and partners serving as external sources of knowledge constitute additional factors that influence organization-level collaboration.

4) Tangible and intangible resources

Inter-organizational level:

A) Power balance (which may indicate type of partner and collaboration mode)

\subsubsection{Technology exploitation through outsourcing}

As for technology exploitation, we considered activities that include the acquisition of products, services, processes, or equipment developed by third parties; the outsourcing of upstream or downstream activities; and outward licensing intellectual property. This is in line with inbound and outbound open innovation (Chesbrough and Bogers, 2014; Dahlander and Gann, 2010) and has important implications for dealing with the paradoxes of knowledge sharing/protection and appropriability (Bogers, 2011; Laursen and Salter, 2014). We investigated during which stages of the value chain they take place. Despite the SMEs in our researched ecosystem not having any patents (and therefore being unable to license them), they value the outsourcing of various activities (Rahman and Ramos, 2013). Outsourcing/collaboration might be perceived as knowledge flows across organizational boundaries, which also implies mutually dependent inflows and outflows (Cassiman and Valentini, 2016). This highlights the interactive nature of knowledge flows between different stakeholders as well as the strong dependency between them, as one company's inflow is another’s outflow (Enkel et al., 2009; Tranekjer and Knudsen, 2012).

The efficient utilization of external knowledge sources seems to contribute strongly to open innovation development in SMEs. SMEs appear to be more aware of outsourcing opportunities; due to their size and financial resources, some have to outsource R\&D or the manufacturing of some components (Radziwon and Bogers, 2018; Teirlinck and Spithoven, 2013; Vanhaverbeke, 2017). 
For some SMEs (Table 4 Company B1, D1, E1, G1), the outsourcing of various parts of the business provides a way to focus on developing core competencies, which can lead to specialization (Table 4 Company D2, E2). This is usually due to a reverse effect of "not invented here” (NIH) syndrome (Antons and Piller, 2015; Katz and Allen, 1982) and "not shared here” (NSH) syndrome (Burcharth et al., 2014). They have neither the time (Table 5 Company D1) nor the money to acquire competencies from various different fields. For them, focusing on their core competencies and getting better at what they already do is much more beneficial than trying to do everything (Table 5 Company D2, E2).

The interest in technology exploration in case of SMEs could be explained by the research view of the firm that assumes that all of the assets, resources, and capabilities that a company possesses are unique and that their inimitable combinations form its competitive advantage (Barney 1991). That is why, in order to gain a competitive edge, the company should increase, improve, and fully utilize all its assets. Traditionally, the resources and assets contain common production factors such as labor, capital, and human capital. As long as the assets contain only those listed, the resource-based view can be considered an overly inward-looking view of the firm. However, the emphasis in research has recently shifted towards analyzing the role and impact of intangible factors of production, such as relational and social capital, organizational practices, and intellectual property rights (IPR). The involvement of these factors facilitates the extension of the set of internal production factors. According to resource based view, R\&D and other collaboration (e.g., alliances) are implemented in order to draw maximum benefits from existing resources; acquire complementary skills and resources; enter new markets; create new products; and retain innovation capabilities (Dickson et al., 2006; Sakakibara 2002). Due to scarcity or lack of tangible and/or intangible resources on the organizational level (which could reflect the product and technology readiness and complexity), outsourcing could be one of the forms of incorporating additional resources 
through inter-organizational collaboration (Granstrand and Sjölander, 1990). These activities establish new ties and create interdependencies, both between stakeholders within and outside of the ecosystem. In this manner, technology exploitation offers as a way to enhance new knowledge and skills to the entire ecosystem.

\subsubsection{Technology exploration}

In terms of technology exploration, we focused our research on the sources of knowledge and technologies, and the activities that enable firms to acquire them (Van de Vrande et al., 2009). Following Laursen and Salter (2006) and others who build on the Community Innovation Survey (CIS), we consider external sources of information, including market sources; commercial labs, private R\&D organizations, and consultants; institutional sources, government, and public research organizations; as well as other sources such as industrial associations, trade fairs, exhibitions and conferences, scientific journals, and trade/technical publications. Diverse sources of knowledge combined with inter-organizational collaboration are also crucial for SME performance (Powell et al., 1996). For some, networking and good references are their primary source of new customers (Table 5 Company A1, B1, D1). Some SMEs therefore state that their customers are their main source of external knowledge (Table 4 Company A3, D2, E4). However, our findings show that, in this ecosystem, SMEs recognize suppliers as one of their key business partners (Table 4 Company A1, B2, G2). Good relationships with suppliers could not only assure good service but also knowledge about the newest technology and possible product optimization (Table 4 Company B, C, D). Instead of acquiring knowledge by themselves, some companies prefer to partner with those who already have this specific knowledge. This might be why, for some SMEs, (Table 4 Company G2 ) suppliers are not only a part of their vertical network but an important business partner, which helps the SME develop and deliver a value proposition to the customer (Rothwell and Dodgson, 1991). 
External knowledge sourcing through technology exploration could also be linked to resource based view and the need to acquire both tangible and intangible resources from outside of the organizational level. Nevertheless, it is also strongly related to the type of partnership and choice of collaboration mode expressed by power balance on an inter-organizational level. In this way, partner choice, organization, and the governance of the cooperative relationship are not only addressed but could be also explained by transaction cost economics (Williamson 1981). This approach focuses on the transaction and its governance as a way to create order, alleviate conflict, and achieve mutual gains. It is based on the fundamental observation that perfect markets are non-existent. In perfect markets, all costs incurred in transactions would be solely related to the exchange of a good or service - no additional costs would be involved. In the world of asymmetric and precious information, incomplete contracts, and other uncertainties, the costs incurred in "pure exchanges” are augmented by transaction costs. Transaction costs are the price paid for searching, contracting, monitoring, and enforcing costs (Hennart 1993; North 1990; Williamson 1985). Cooperation and other forms of engagement with external partners are common ways to reduce the inherently risky nature of $R \& D$ activities. Arrangements with external partners may increase the transaction costs, however, unless the interdependencies between stakeholders are strong enough. Strong interdependencies between ecosystem members possibly lower the risk of inappropriate behavior due to severe consequences not only from unsatisfied partners but from all ecosystem members. In this way, firms that build trust and credibility among possible ecosystem partners may have a low propensity to commit consciously to inappropriate behavior due to potential reputation issues. Furthermore, contractual agreements - one of the factors that could potentially lower transaction costs - may not be so crucial in ecosystems due to reputationbased, self-regulating mechanisms, which could naturally eliminate not only inappropriate behaviors in general but possibly even firms that consciously commit to them. 


\subsection{Exploring challenges in the adoption and management of open innovation strategies}

While exploring challenges in the adoption of open innovation strategies in Portuguese SMEs, Rahman and Ramos (2013) found that one of the general constraints was the lack of market demand resulting from the low customer purchasing power. They suggest that SMEs may not necessarily understand customer needs well, which could be resolved by the better implementation of open innovation principles. Our study complements these findings by providing a different explanation of the demand issues.

Insert Table 5 about here

Some of the interviewed ecosystem members (Table 5 Company D2, E1, F3) brought up the topic of challenges related to market and customer readiness to understand and buy technologically advanced products. This might be particularly true for SMEs engaging in more radical innovations, which according to Wynarczyk (2013) are enabled by open innovation practices that enhance their innovation capability. While this would not usually be a major problem for large companies, it could create a meaningful obstacle for SMEs. In this respect, we have identified two challenges. The first is to create market demand and convince customers to buy (Rahman and Ramos, 2013). Consequently, companies must make numerous investments to reach their customers after having invested to develop their product, which is also very much aligned with the findings of Rahman and Ramos (2013), who classify this as a supply-side challenge. The second challenge is the complexity of markets (Table 5 Company C2), which might also include potential expansion to as yet unknown and not very well understood foreign markets (Rothwell and Dodgson 1991). Based on this observation, we derive the third organizational characteristic that could influence inter-organizational collaboration for innovation: 


\section{3) Product, market, and/or customer readiness}

Not only developing the demand on the market is important but also creating something new (i.e., product, process, technology, etc.); however, this requires trust and creditability (Lee et al., 2010; Powell et al., 1996), which might pose a challenge for (sometimes) unknown SMEs (Table 5 Company A2, F2, G1). Moreover, listening to customers and suppliers is not enough in the product development process. SMEs must also be able to contribute their own competences and ideas to the process - otherwise, Ford would have to get customers faster horses (Table 3 Company E2).

Additional challenges in the adoption of open innovation strategies could be connected with IPR or widely understood knowledge leakage. The managing director from Company C1 expressed his concerns related to a potential takeover of knowledge that might occur in collaboration with different stakeholders and competitors (Table 5 Company C1). Moreover, we observed that only this company expressed concern for this potential threat.

Additional input to this discussion relates to the misalignment of "agendas" or “approaches” of potential partners. This was particularly directed towards universities and technology institutes, which have a different focus than the industry (Table 4 Company E5, C1). This tension could emerge and lead to further conflict on the basis of developing new technologies intended to generate research papers versus their implementation in the products aimed at generating profit. Nevertheless, a university (Table 4 Company C1, E5) and other external partners - other than suppliers and customers (Table 6 Company E, F, G) - might still be a good source of knowledge and ideas (Etzkowitz and Leydesdorff, 2000; Shan et al., 1994). Furthermore, both the development of market demand and concerns related to potential knowledge spillovers could lead to inter-organizational factors that might either increase their propensity to enter collaboration or lower the entry risks. The factors that we could derive thus far are: 


\section{B) Trust and credibility (which could potentially influence a firm's reputation) \\ C) Contractual agreements (which may assure IPR protection)}

\section{Conclusion}

\section{Contributions and implications}

This study explores how SMEs perceive, organize, and manage open innovation in the context of a regional innovation ecosystem. This is in response to the call for more research on open innovation across levels of analysis (Bogers et al., 2017; West et al., 2014). Our findings point out that despite various interdependencies between ecosystem members, the understanding of what innovation and knowledge-based collaboration comprise can differ widely. This may be linked to the differences between SME business models, which form the overall ecosystem model of value creation and capture (cf. Radziwon et al., 2017; Ritala et al., 2013; Van Der Borgh et al., 2012). Acknowledging such inconsistencies is important for managers who want to collaborate in or develop an innovation ecosystem. Our findings thus contribute to the understanding of how ecosystems develop dynamically, clarifying some attributes of the underlying complexity (Davis, 2016; Holgersson et al., 2017; Rohrbeck et al., 2009), and how it may match other aspects of corporate activities (e.g., Adner, 2006; Adner and Kapoor, 2010).

Our empirical findings show that path dependencies (in terms of collaborative traditions) influence the extent to which SMEs are open to external sources of innovation. There is also a strong relation to the extent to which local firms risk joining various innovative partnerships. Generally, the existing interdependencies drive this dynamic co-evolution (Figure 1). Moreover, our analyses unfold a multilevel structure of the ecosystem. Despite the main focus of this study being inter-organizational collaboration, we could also distinguish between the organization-level factors that influence the relationship-building choices of these firms. 
Due to very strong interdependencies observed on the inter-organizational level, the decisions made by firms and their consequences may influence the entire ecosystem.

Furthermore, different ways of organizing open innovation practices might not only provide a source of knowledge for the ecosystem members, they might also bring companies closer to one another in terms of potential partnerships on new initiatives. SMEs' dependence on open innovation together with their openness to collaboration with various partners indicate that they can also (i.e., not only large companies) be involved in the coopetition relationships, while this could also become the selective domain of SMEs embedded in an open business ecosystem. Such an SME-specific perspective in the context of ecosystems implies a crucial role for these members when developing future projects and related initiatives (cf. Brunswicker and Van de Vrande, 2014; Van de Vrande et al., 2009).

Managing innovation in SMEs is not only about key performance indicators, tracking the return on investments on new products, and R\&D expenditure. It usually concerns not only the challenge of choosing the right partners (who can and will deliver on time) and finding customers who will pay on time but also how to achieve additional synergies that could increase the credibility of small firms. Instead of reinventing the wheel, SMEs could focus on capturing the knowledge and learning located within their ecosystem. So-called localized learning is based on knowledge embedded within a system of collocated stakeholders (Malmberg and Maskell, 1997; Maskell and Malmberg, 1999). Geographical proximity could act as an enabler of knowledge transfer (Maskell 2001). In this way, stakeholders embedded in an ecosystem could co-evolve and co-develop through the joint learning process. Through knowledge disclosure from the organizational to the inter-organizational level and opening up for external sources of knowledge flowing from the inter-organizational level to organizational level (thus creating an open innovation environment), ecosystem stakeholders could assure the learning process of the entire ecosystem. 
We also believe that the empirical findings make an important contribution to both academics and practitioners. From the theoretical perspective, they add both to the open innovation literature focusing specifically on SMEs (Brunswicker and Vanhaverbeke, 2015; Radziwon and Bogers, 2018; Vanhaverbeke et al., 2012) and to the literature related to regional collaboration and business ecosystem development (Rong et al., 2013). Thus, the ecosystem level becomes an important unit of analysis with particular emphasis on the role of SMEs (Chesbrough et al., 2014; West et al., 2014). The context of openness in manufacturing and process technology also emphasizes the importance of broadening the typical scope of $R \& D$ and product technologies in open innovation research (Chesbrough and Bogers, 2014). Last but not least, our findings extend the position advanced by Mitra (2017) by providing a concrete SME-based example of his classification. In particular, we highlight the importance of the type of innovation that SMEs choose and their understanding of the process in terms of how the form of innovation (in our case open innovation) is performed.

Practically, we believe that our findings may serve as guidelines for SMEs that are involved in different types of collaboration or wish to do so. Some of the important factors on the organizational and inter-organizational levels that SMEs could consider when selecting appropriate partners are regulation-, market-, customer-, and/or user-driven firms; product and/or technology complexity; product, market, and/or customer readiness; tangible and intangible resources; power balance; trust and credibility; and contractual agreements. These factors could be directly translated to questions that managers could consider. On the organizational level, the company should be aware of its main innovation drivers: Do we innovate because we need to catch up with new regulations? Is it the development of new technological solutions that stimulates us to seek innovative solutions? Is it the customer that is (potentially) waiting for some new solutions to their problems? Alternatively, there could also be pressure for competition that provides the motivation to do things differently - and 
ideally much better. Next, the company should consider the level of complexity that they are dealing with as well as evaluating if potential collaborators might help them with the development of technology, a particular product, or maybe a service. It is also crucial to investigate (or realize) if the customer and market are ready for coming innovations and if the company is ready to approve high-risk/high-gain projects. It is also important to realize what kind of tangible and intangible resources the company owns/has and what is still missing. Stepping into the inter-organizational zone thus opens up for external sources of knowledge, and companies must ask themselves if they prefer a known (and thus implicitly trusted) or yet unknown partner. Which of them could currently make the greatest contribution to their current project portfolio? Should the partner be big (maybe more credible) or small? How will the power be distributed in this potential relationship? Last but not least is the level of contractual agreements. Is it necessary to formalize the collaboration on paper or is an informal relationship agreement enough to avoid harming any of the partners? What will happen to jointly developed IPR if one of the partners loses interest in the relationship? Answering some of these questions might not only help in increasing the understanding of the drivers of inter-SME collaboration but also prepare managers to deal with various challenges in project and process management, especially when deciding whether to join a collaborative relationship in a regional ecosystem setup.

\section{Limitations and future research}

The main limitations of this study relate to the choice of a particular region with special characteristics; in this case, a mix of high and low tech. This raises questions as to what extent our findings could be replicable for other ecosystems with a substantial number of SMEs. Further research could include comparative studies of two or three ecosystems from different countries and representing different cultural origins or maybe “mixed” ecosystems in terms of companies' strategic profiles; this could involve a mix of high-tech and low-tech companies 
with service-oriented enterprises. Alternatively, the factors highlighted in our study could serve as a good basis for the further development of quantitative study. Such studies could test which of them have the most significant influence on the process of establishing new collaboration for innovation.

Secondly, while our study takes the ecosystem with embedded SMEs as a unit of analysis for understanding open innovation processes and practices, further research could focus more on different - possibly also multiple - levels of analysis (Gupta et al., 2007; West et al., 2006). Other units of analysis could focus more on the individual level of open innovation in a business ecosystem. This approach could concern managers and company executives and their role in value creation or in single-firm contributions to ecosystem value capturing. The role of the "gatekeepers" in managing knowledge flows across organizational boundaries within the ecosystem could also be usefully explored. Another interesting unit of analysis could refer to inter-ecosystem relationships and how different ecosystems interact with one another, as well as the role of SMEs embedded in various different ecosystems.

Our research findings identify the need to set clear goals and business objectives for the ecosystem (Adner, 2006; Adner and Kapoor, 2010; Ritala et al., 2013), which implies a need for the further investigation of ecosystem leadership and a form of management that might be suitable for the ecosystem members. Should the leader come from inside or outside of the ecosystem? If an outsider, how would it get the commitment of all members? If an insider, should this person come from a large company enterprise or from an SME?

Last but not least, our research focuses very much on SMEs, their interaction, and their collaboration with other ecosystem stakeholders. In order to analyze these interactions, we take the open innovation lens, which assumes purposive inflows and outflows of knowledge across organizational boundaries. Building on various types of knowledge and their sources, further research could explore knowledge exchange and management and try to analyze 
commonalities and differences in this respect between ecosystem and territorial approach (Scaringella and Radziwon, 2018). In principle, these studies could touch upon digital transformation and the accumulation of easily accessible knowledge and how it is used (Rindfleisch et al., 2017). 


\section{References}

Adner, R., 2006. Match your innovation strategy to your innovation ecosystem. Harvard Business Review. 84(4), 98-107.

Adner, R., Kapoor, R., 2010. Value creation in innovation ecosystems: how the structure of technological interdependence affects firm performance in new technology generations. Strategic Management Journal. 31(3), 306-333.

Afuah, A., 2000. How much do your co-opetitors' capabilities matter in the face of technological change? Strategic Management Journal. 21(3), 387-404.

Ahn, J.M., Minshall, T., Mortara, L., 2018. How do entrepreneurial leaders promote open innovation adoption in small firms? In Vanhaverbeke, W., Frattini, F., Roijakkers, N., Usman, M. (Eds.), Researching Open Innovation in SMEs.

Anderson, R.W., Acur, N., Corney, J., 2018. How do SMEs use open innovation when developing new business models? In Vanhaverbeke, W., Frattini, F., Roijakkers, N., Usman, M. (Eds.), Researching Open Innovation in SMEs, pp. 179-209.

Antons, D., Piller, F.T., 2015. Opening the black box of "not invented here:” attitudes, decision biases, and behavioral consequences. Academy of Management Perspectives. 29(2), 193-217.

Asheim, B.T., Coenen, L., 2005. Knowledge bases and regional innovation systems: comparing Nordic clusters. Research Policy. 34(8), 1173-1190.

Barney, J., 1991. Firm resources and sustained competitive advantage. Journal of Management. 17(1), 99-120.

Bianchi, M., Campodall'Orto, S., Frattini, F., \& Vercesi, P., 2010. Enabling open innovation in small-and medium-sized enterprises: how to find alternative applications for your technologies. R\&D Management. 40(4), 414-431.

Bogers, M., 2011. The open innovation paradox: knowledge sharing and protection in R\&D collaborations. European Journal of Innovation Management. 14(1), 93-117.

Bogers, M., Afuah, A., Bastian, B., 2010. Users as innovators: a review, critique, and future research directions. Journal of Management. 36(4), 857-875.

Bogers, M., Zobel, A.-K., Afuah, A., Almirall, E., Brunswicker, S., Dahlander, L.,

Frederiksen, L., Gawer, A., Gruber, M., Haefliger, S. and others, 2017. The open innovation research landscape: established perspectives and emerging themes across different levels of analysis. Industry and Innovation. 24(1), 8-40.

Brunswicker, S., Vanhaverbeke, W., 2015. Open innovation in small and medium-sized enterprises (SMEs): external knowledge sourcing strategies and internal organizational facilitators. Journal of Small Business Management. 53(4), 1241-1263. 
Brunswicker, S., Van de Vrande, V., 2014. Exploring open innovation in small and mediumsized enterprises. In Chesbrough, H., Vanhaverbeke, W. West, J. (Eds.), New Frontiers in Open Innovation. Oxford University Press, Oxford, pp. 135-156.

Burcharth, A.L. de A., Knudsen, M.P. Søndergaard, H.A., 2014. Neither invented nor shared here: the impact and management of attitudes for the adoption of open innovation practices. Technovation. 34(3), 149-161.

Cassiman, B., Valentini, G., 2016. Open innovation: are inbound and outbound knowledge flows really complementary? Strategic Management Journal. 37(6), 1034-1046.

Chesbrough, H., 2003. Open Innovation: The New Imperative for Creating and Profiting from Technology. Harvard Business School Press, Boston, MA.

Chesbrough, H., 2006. Open Innovation: The New Imperative for Creating and Profiting from Technology. Harvard Business Press, Boston, MA.

Chesbrough, H., Bogers, M., 2014. Explicating open innovation: clarifying an emerging paradigm for understanding innovation. In H. Chesbrough, W. Vanhaverbeke, J. West (Eds.), New Frontiers in Open Innovation. Oxford University Press, Oxford, pp. 3-28.

Chesbrough, H., Vanhaverbeke, W., West, J., 2014. New Frontiers in Open Innovation. Oxford University Press, Oxford.

Corbin, J., Strauss, A., 1990. Basics of Qualitative Research: Grounded Theory Procedures and Techniques. Sage, Newbury Park, CA.

Dahlander, L., Gann, D.M., 2010. How open is innovation? Research Policy. 39(6), 699-709.

Davis, J.P., 2016. The group dynamics of interorganizational relationships: collaborating with multiple partners in innovation ecosystems. Administrative Science Quarterly. 61(4), 621661.

Dell'Era, C., Magistretti, S., Verganti, R., 2018. Exploring collaborative practices between SMEs and designers in the Italian furniture industry. In Vanhaverbeke, W., Frattini, F., Roijakkers, N., Usman, M. (Eds.), Researching Open Innovation in SMEs.

Dickson, P.H., Weaver, K.M. Hoy, F., 2006. Opportunism in the R\&D alliances of SMES: the roles of the institutional environment and SME size. Journal of Business Venturing. 21(4), 487-513.

Dodgson, M., Gann, D., Salter, A., 2006. The role of technology in the shift towards open innovation: the case of Procter \& Gamble. R\&D Management. 36(3), 333-346.

Dougherty, D., 2002. Grounded theory research methods. In Baum, J.A.C. (Ed.), The Blackwell Companion to Organizations. Blackwell, Oxford, pp. 849-866.

Eftekhari, N., Bogers, M., 2015. Open for entrepreneurship: how open innovation can foster new venture creation. Creativity and Innovation Management. 24(4), 574-584. 
Eisenhardt, K.M., 1989. Building theories from case study research. Academy of Management Review. 14(4), 532-550.

Eisenhardt, K.M., Galunic, D.C., 2000. Coevolving: at last, a way to make synergies work. Harvard Business Review. 78(1), 91-102.

Eisenhardt, K.M., Graebner, M.E., 2007. Theory building from cases: opportunities and challenges. Academy of Management Journal. 50(1), 25-32.

Enkel, E., Gassmann, O., Chesbrough, H., 2009. Open R\&D and open innovation: exploring the phenomenon. R\&D Management. 39(4), 311-316.

Etzkowitz, H., Leydesdorff, L., 2000. The dynamics of innovation: from national systems and "mode 2" to a triple helix of university - industry - government relations. Research Policy. 29(2), 109-123.

Franke, N., Von Hippel, E., 2003. Satisfying heterogeneous user needs via innovation toolkits: the case of Apache security software. Research Policy. 32(7), 1199-1215.

Freel, M.S., 2003. Sectoral patterns of small firm innovation, networking and proximity. Research Policy. 32(5), 751-770.

Gassmann, O., 2006. Opening up the innovation process: towards an agenda. R\&D Management. 36(3), 223-228.

Gioia, D.A., Corley, K.G., Hamilton, A.L., 2012. Seeking qualitative rigor in inductive research: notes on the Gioia Methodology. Organizational Research Methods. 16(1), 1531.

Giudici, G., Rossi-Lamastra, C., 2018. Crowdfunding of SMEs and startups: when open investing follows open innovation. In Vanhaverbeke, W., Frattini, F., Roijakkers, N., Usman, M. (Eds.), Researching Open Innovation in SMEs.

Glaser, B., Strauss, A., 1967. The Discovery of Grounded Theory: Strategies for Qualitative Research. Aldine Transaction Books, Chicago.

Granstrand, O., Patel, P., Pavitt, K., 1997. Multitechnology corporations: why they have "distributed” rather than "distinctive core” capabilities. California Management Review. 39(4), 8-25.

Granstrand, O., Sjölander, S., 1990. Managing innovation in multi-technology corporations. Research Policy. 19(1), 35-60.

Gupta, A.K., Tesluk, P.E., Taylor, M.S., 2007. Innovation at and across multiple levels of analysis. Organization Science. 18(6), 885-897.

Hennart, J.-F., 1993. Explaining the swollen middle: why most transactions are a mix of “market” and "hierarchy." Organization Science. 4(4), 529-547. 
Holgersson, M., Granstrand, O., Bogers, M., 2017. The evolution of intellectual property strategy in innovation ecosystems: uncovering complementary and substitute appropriability regimes. Long Range Planning. forthcoming

Hossain, M., 2018. Adoption of open innovation by small firms to develop frugal innovations for inclusive development. In Vanhaverbeke, W., Frattini, F., Roijakkers, N., Usman, M. (Eds.), Researching Open Innovation in SMEs.

Huston, L., Sakkab, N., 2006. Connect and develop. Harvard Business Review. 84(3), 58-66.

Iansiti, M., Levien, R., 2004. Strategy as ecology. Harvard Business Review. 82(3), 68-81.

Kanter, R.M., 2012. Enriching the ecosystem. Harvard Business Review. 90(3), 140-147.

Katz, R., Allen, T.J., 1982. Investigating the not invented here (NIH) syndrome: a look at the performance, tenure, and communication patterns of $50 \mathrm{R} \& \mathrm{D}$ project groups. $\mathrm{R} \& \mathrm{D}$ Management. 12(1), 7-20.

Kirschbaum, R., 2005. Open innovation in practice. Research-Technology Management. 48(4), 24-28.

Kogut, B., Shan, W., Walter, G., 1992. The make-or-cooperate decision in the context of an industry network. In M. Granovetter, N. Nohria, R.G. Eccles (Eds.), Networks and Organizations: Structure, Form, and Action. Harvard Business School Press, Boston, MA, pp. 25-56.

Laursen, K., Salter, A., 2006. Open for innovation: the role of openness in explaining innovation performance among UK manufacturing firms. Strategic Management Journal. 27(2), 131-150.

Laursen, K., Salter, A., 2014. The paradox of openness: appropriability, external search and collaboration. Research Policy. 43(5), 867-878.

Lee, S., Park, G., Yoon, B., \& Park, J., 2010. Open innovation in SMEs: an intermediated network model. Research Policy. 39(2), 290-300.

Locke, K., 2001. Grounded Theory in Management Research. Sage, Thousand Oaks, CA.

Lundvall, B. Å., Johnson, B., Andersen, E. S., \& Dalum, B., 2002. National systems of production, innovation and competence building. Research Policy. 31(2), 213-231.

Malmberg, A., Maskell, P., 1997. Towards an explanation of regional specialisation and industry agglomeration. European Planning Studies. 5, 25-42.

Maskell, P., 2001. Towards knowledge based theory of the geographical cluster. Industrial and Corporate Change. 10, 921-943.

Maskell, P., Malmberg, A., 1999. Localised learning and industrial competitiveness. Cambridge Journal of Economics. 23(2), 167-185. 
Massa, S., Testa, S., 2008. Innovation and SMEs: misaligned perspectives and goals among entrepreneurs, academics, and policy makers. Technovation. 28(7), 393-407.

Mitra, J., 2017. The Business of Innovation. Sage.

Moore, J.F., 1993. Predators and prey: a new ecology of competition. Harvard Business Review. 71(3), 75-86.

Moore, J.F., 1996. The Death of Competition: Leadership and Strategy in the Age of Business Ecosystems. Harper Business, New York.

Moulaert, F., Sekia, F., 2003. Territorial innovation models: a critical survey. Regional Studies. 37(3), 289-302.

Narula, R., 2004. R\&D collaboration by SMEs: new opportunities and limitations in the face of globalisation. Technovation. 24(2), 153-161.

North, D.C., 1990. Institutions, Institutional Change and Economic Performance. Cambridge University Press, Cambridge.

Oakey, R.P., 2013. Open innovation and its relevance to industrial research and development: the case of high-technology small firms. International Small Business Journal. 31(3), 319336.

Oh, D.-S., Phillips, F., Park, S. and Lee, E. 2016. Innovation ecosystems: a critical examination. Technovation. 54, 1-6.

Pop, O.M., Roijakkers, N., Rus, D., Hins, M., 2018 The link between entrepreneurial attributes and SME ecosystem orchestration: a case from the Dutch HR services industry. In Vanhaverbeke, W., Frattini, F., Roijakkers, N., Usman, M. (Eds.), Researching Open Innovation in SMEs.

Powell, W.W., Koput, K.W., Smith-Doerr, L., 1996. Interorganizational collaboration and the locus of innovation: networks of learning in biotechnology. Administrative Science Quarterly. 41(4), 116-145.

Radziwon, A., 2017. Exploring Inter-organizational Collaboration for Innovation in a Regional Ecosystem. University Press of Southern Denmark, Odense.

Radziwon, A., Bogers, M., 2018. Managing SMEs’ collaboration across organizational boundaries within a regional business ecosystem. In Vanhaverbeke, W., Frattini, F., Roijakkers, N., Usman, M. (Eds.), Researching Open Innovation in SMEs. pp. 213-248.

Radziwon, A., Bogers, M. Bilberg, A. 2017. Creating and capturing value in a regional innovation ecosystem: a study of how manufacturing SMEs develop collaborative solutions. International Journal of Technology Management. 75(1-4), 73-96.

Rahman, H., Ramos, I., 2013. Challenges in adopting open innovation strategies in SMEs: an exploratory study in Portugal. Issues in Informing Science and Information Technology. 
pp. 431-448.

Rindfleisch, A., O’Hern, M., Sachdev, V., 2017. The digital revolution, 3D printing, and innovation as data. Journal of Product Innovation Management. 34(5), 681-690.

Ritala, P., Agouridas, V., Assimakopoulos, D. and Gies, O., 2013. Value creation and capture mechanisms in innovation ecosystems: a comparative case study. International Journal of Technology Management. 63(3), 244-267.

Ritala, P., Hurmelinna-Laukkanen, P., 2009. What's in it for me? Creating and appropriating value in innovation-related coopetition. Technovation. 29(12), 819-828.

Rohrbeck, R., Hoelzle, K., Gemünden, H.G., 2009. Opening up for competitive advantage: how Deutsche Telekom creates an open innovation ecosystem. R\&D Management. 39(4), 420-430.

Rong, K., Lin, Y., Shi, Y., \& Yu, J., 2013. Linking business ecosystem lifecycle with platform strategy: a triple view of technology, application and organisation. International Journal of Technology Management. 62(1), 7594.

Rothwell, R., Dodgson, M., 1991. External linkages and innovation in small and mediumsized enterprises. R\&D Management. 21(2), 125-138.

Sakakibara, M., 2002. Formation of R\&D consortia: industry and company effects. Strategic Management Journal. 23(11), 1033-1050.

Scaringella, L., Radziwon, A., 2018. Innovation, entrepreneurial, knowledge, and business ecosystems: old wine. Technological Forecasting and Social Change. Forthcoming.

Shan, W., Walker, G., Kogut, B., 1994. Interfirm cooperation and startup innovation in the biotechnology industry. Strategic Management Journal. 15(5), 387-394.

Spithoven, A., Vanhaverbeke, W., Roijakkers, N., 2013. Open innovation practices in SMEs and large enterprises. Small Business Economics. 41(3), pp.1-26.

Sternberg, R., 1999. Innovative linkages and proximity: empirical results from recent surveys of small and medium sized firms in German regions. Regional Studies. 33(6), 529-540.

Teirlinck, P., Spithoven, A., 2013. Research collaboration and R\&D outsourcing: different R\&D personnel requirements in SMEs. Technovation. 33(4-5), 142-153.

Tranekjer, T.L., Knudsen, M.P., 2012. The (unknown) providers to other firms’ new product development: what's in it for them? Journal of Product Innovation Management. 29(6), 986-999.

Vanhaverbeke, W., 2017. Managing Open Innovation in SMEs. Cambridge University Press.

Vanhaverbeke, W., Frattini, F., Roijakkers, N., Usman, M., (Eds.) 2018. Researching Open Innovation in SMEs. World Scientific. 
Vanhaverbeke, W., Vermeersch, I., De Zutter, S., 2012. Open Innovation in SMEs: How Can Small Companies and Start-ups Benefit from Open Innovation Strategies? Flanders DC study.

Van de Vrande, V., De Jong, J.P., Vanhaverbeke and W., De Rochemont, M., 2009. Open innovation in SMEs: trends, motives and management challenges. Technovation. 29(6), 423-437.

Van der Borgh, M., Cloodt, M., Romme, A., 2012. Value creation by knowledge-based ecosystems: evidence from a field study. R\&D Management. 42(2), 150-169.

Von Hippel, E., 1994. "Sticky information" and the locus of problem solving: implications for innovation. Management Science. 40(4), 429-439.

Usman, M., Roijakkers, N., Vanhaverbeke, W., Frattini, F., 2018. A systematic review of the literature on open innovation in SMEs. In Vanhaverbeke, W., Frattini, F., Roijakkers, N., Usman, M. (Eds.), Researching Open Innovation in SMEs.

West, J., Salter, A., Vanhaverbeke, W., \& Chesbrough, H., 2014. Open innovation: the next decade. Research Policy. 43(5), 805-811.

West, J., Bogers, M., 2014. Leveraging external sources of innovation: a review of research on open innovation. Journal of Product Innovation Management. 31(7), 814-831.

West, J., Bogers, M., 2017. Open innovation: current status and research opportunities. Innovation: Organization \& Management. 19(1), 43-50.

West, J., Lakhani, K.R., 2008. Getting clear about communities in open innovation. Industry and Innovation. 15(2), 223-231.

West, J., Vanhaverbeke, W., Chesbrough, H., 2006. Open innovation: a research agenda. In Chesbrough, H., and Vanhaverbeke, W., West, J. (Eds.), Open Innovation: Researching a New Paradigm. Oxford University Press, Oxford, 285-307.

Williamson, O.E., 1981. The economics of organization: the transaction cost approach. American Journal of Sociology. 548-577.

Williamson, O.E., 1985. The Economic Institutions of Capitalism: Firms, Markets, Relational Contracting. Free Press, New York.

Wynarczyk, P., 2013. Open innovation in SMEs: a dynamic approach to modern entrepreneurship in the twenty-first century. Journal of Small Business and Enterprise Development. 20(2), 258-278.

Yin, R.K., 2003. Case Study Research: Design and Methods. Sage, Thousand Oaks, CA.

Zott, C., Amit, R., Massa, L., 2011. The business model: recent developments and future research. Journal of Management. 37(4), 1019-1042. 
Table 1

Key ecosystem elements

\begin{tabular}{|c|c|c|c|}
\hline Element & Definition & Conceptualization & Expression \\
\hline co-evolution & $\begin{array}{l}\text { "An economic community supported by a foundation } \\
\text { of interacting organizations and individuals [...] } \\
\text { produces goods and services of value to customers, } \\
\text { who are themselves members of the ecosystem. The } \\
\text { member organisms also include suppliers, lead } \\
\text { producers, competitors, and other stakeholders. Over } \\
\text { time, they coevolve their capabilities and roles, and } \\
\text { tend to align themselves with the directions set by one } \\
\text { or more central companies." (Moore 1996), p. 26) }\end{array}$ & $\begin{array}{l}\text { We distinguish between } \\
\text { evolution, which is a self- } \\
\text { driven mechanism, and } \\
\text { development, which tends to } \\
\text { be externally moderated. }\end{array}$ & $\begin{array}{l}\text { This element could be expressed by } \\
\text { both formal and informal previous } \\
\text { experience with collaboration. }\end{array}$ \\
\hline Interdependencies & $\begin{array}{l}\text { "The company can focus its resources on product } \\
\text { design, quality assurance, marketing, and customer } \\
\text { support. At the same time, its interdependencies mean } \\
\text { the company must share the fate of the other } \\
\text { participants in the ecosystem." (Iansiti and Levien, } \\
\text { 2004), p. 76) }\end{array}$ & $\begin{array}{l}\text { Through interactions, } \\
\text { ecosystem stakeholders } \\
\text { develop various ties (both } \\
\text { weak and strong); } \\
\text { nevertheless, the crucial } \\
\text { element is co-dependence on } \\
\text { future survival. }\end{array}$ & $\begin{array}{l}\text { This element could be expressed in } \\
\text { terms of the presence of both firms' } \\
\text { immediate customer-supplier network } \\
\text { and the extended one taking into } \\
\text { consideration other ecosystem } \\
\text { stakeholders. }\end{array}$ \\
\hline Orchestration & $\begin{array}{l}\text { An orchestrator or a keystone player could potentially } \\
\text { "exercise a system-wide role despite being only a } \\
\text { small part of their ecosystems' mass.” (Iansiti and } \\
\text { Levien, 2004), p. 74). An effective keystone strategy } \\
\text { could cover value creation and sharing with other } \\
\text { ecosystem participants (Iansiti and Levien, 2004)). }\end{array}$ & $\begin{array}{l}\text { We primarily focus on the } \\
\text { presence of both actual or } \\
\text { potential orchestrator(s) in the } \\
\text { ecosystem. }\end{array}$ & $\begin{array}{l}\text { This element was considered when } \\
\text { selecting the region; namely, there are } \\
4 \text { large players [Company K, J, Y, and } \\
\text { Z], which could potentially play or take } \\
\text { this role. }\end{array}$ \\
\hline Proximity & $\begin{array}{l}\text { Ecosystem literature distinguishes between close } \\
\text { proximity (Iansiti and Levien, 2004) like inherently } \\
\text { local territory, which could be country or region } \\
\text { (Kanter, 2012), and virtual proximity }\end{array}$ & $\begin{array}{l}\text { We primarily focus on the } \\
\text { close spatial proximity, which } \\
\text { could provide space for further } \\
\text { interaction. }\end{array}$ & $\begin{array}{l}\text { This element was considered when } \\
\text { selecting the research sample (the } \\
\text { distance between the central city in the } \\
\text { region and the company should be } \\
\text { within } 25 \mathrm{~km} \text { ) }\end{array}$ \\
\hline
\end{tabular}


Figure 2

Multilevel structure of the ecosystem

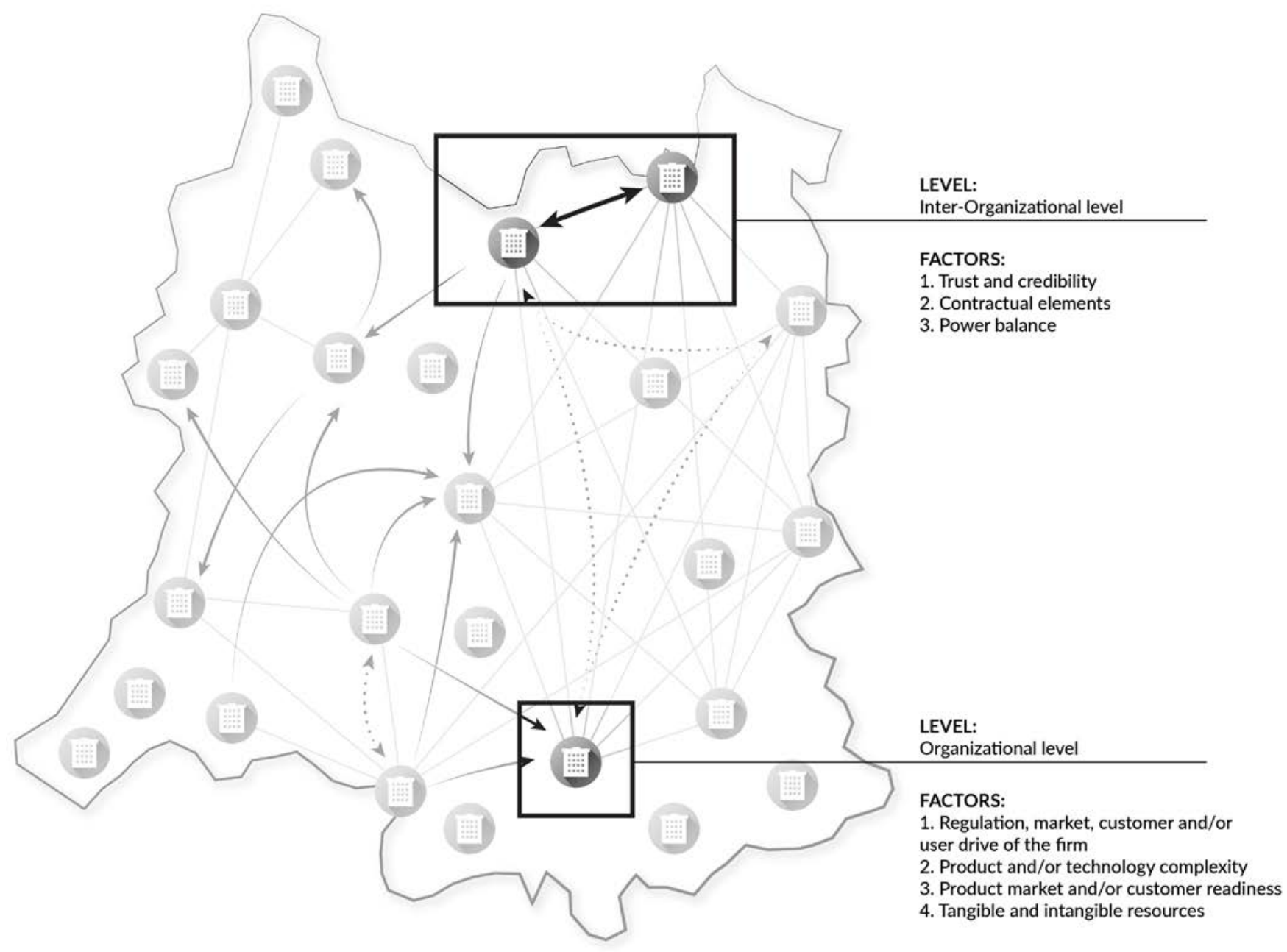


Figure 1

Map of the ecosystem and interdependencies between ecosystem companies

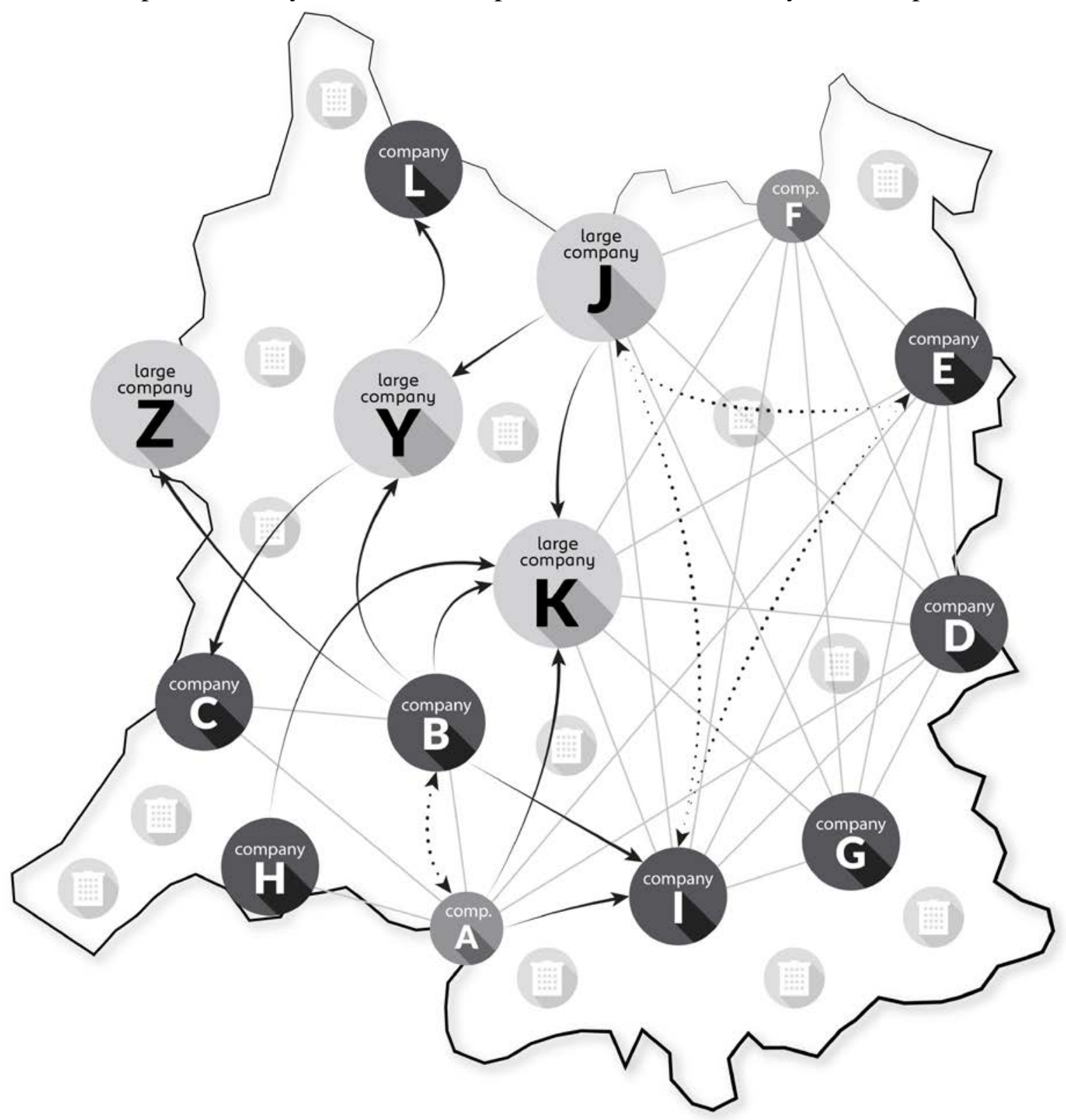

KEY:

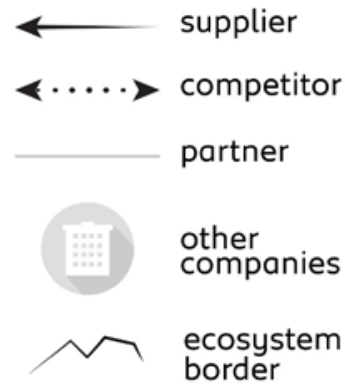


Table 2

Overview of interviews

\begin{tabular}{clll}
\hline Company & Strategic profile & Number of interviews & Interviewee position \\
A & Micro-enterprise & 2 & CEO \\
B & SME & 2 & Technical Manager \\
C & SME & 2 & Managing Director \\
D & SME & 2 & Development Manager \\
E & SME & 2 & Managing Director \\
F & Micro-enterprise & 2 & CEO \\
G & SME & 2 & Managing Director \\
H & SME & 2 & Managing Director \\
I & SME & 1 & Managing Director \& HR Partner \\
J & Large company & 2 & Site Manager \\
K & Large company & 2 & Innovation Director \& Head of R\&D \\
L & SME & CEO \\
\hline
\end{tabular}


Table 3

Perceiving innovation coding scheme 


\section{Illustrative Quotes}

"We have very few standard solutions. We'd like to have some more. But mostly it's about $80 \%$ of our product is customized directly to one purpose."

Company B1

"We're selling all our products to the companies they are building the xxx units. And they all have a strong content of customization. So that's our niche. We have standard platforms and standard products, but we always - or more-less always - customize our products."

\section{Company E1}

"(...) our production is $100 \%$ customized, so we need to be close to our customers, and we focus on quality and we focus on delivery time and so on." Company C1

"That's actually also one of our strengths - that we're able to make a solution for the customer."

Company A1

"I used to say a phrase from what Henry Ford said If I have asked my customers what they really wanted, they would have said a faster horse, because they didn't know it was possible to make a car. So nobody was asking for a car.' (...) if you're only doing what you're asked to do, we don't really do innovations. Because you have to bring in (....) the need, the problems that have to be solved. You need to get from A to B. (...) It is not a faster horse you actually need.

You need to get from A to B if it was back in Henry Ford's time. And then you have to bring in new engineers and the technology - how can we do this. (...) our main target is always to create value for our customer and their customers. Because at the end of the day, we are all trying to create added value for the end customer. (...) So we need to have the knowledge and what is the demand out there and to have this cooperation with our customer and to bring in our own ideas. And not just only do what they all ask us to do but also bring our own ideas." Company E2

"Innovation, in my view, is just having the right products at the right time. I mean, you may have a very, very smart solution, but if it's 5 years too early, I mean, there are no customers for it. So what we do to be innovative is always to look at where the market is heading:"

\section{Company D1}

"I think real innovation starts with what it is that the customer needs, and then we can say 'OK, how should we fulfill it?' It's not actually always what we are doing"

Company C2

"Customers specify the solution, we're making it." Company B2

"I would not say if we're only doing what you asked us to do, we're don't really do innovations."

Company E3

"We do that every day (...) the guys they don't make anything else than new parts, so they do new parts and drawings and development and innovation every day."

\section{Company A2}

"If you say product innovation, we innovate product every time (...) we have one product that is new, and none of our competitors have."

Company C3

\section{First Order Codes}

Theoretical

categories

customization and

standardization level

Statements about the

role of customer and

sustainable technology

in the innovation process

Statements about products that are new to the company and to the customer standardization

Balancing technology push with market pull

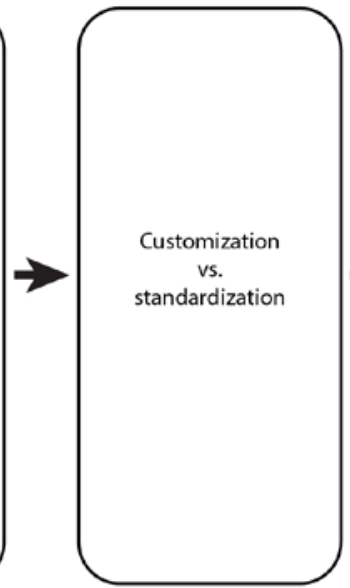


Table 4

Organizing inter-organizational knowledge flows for innovation coding scheme

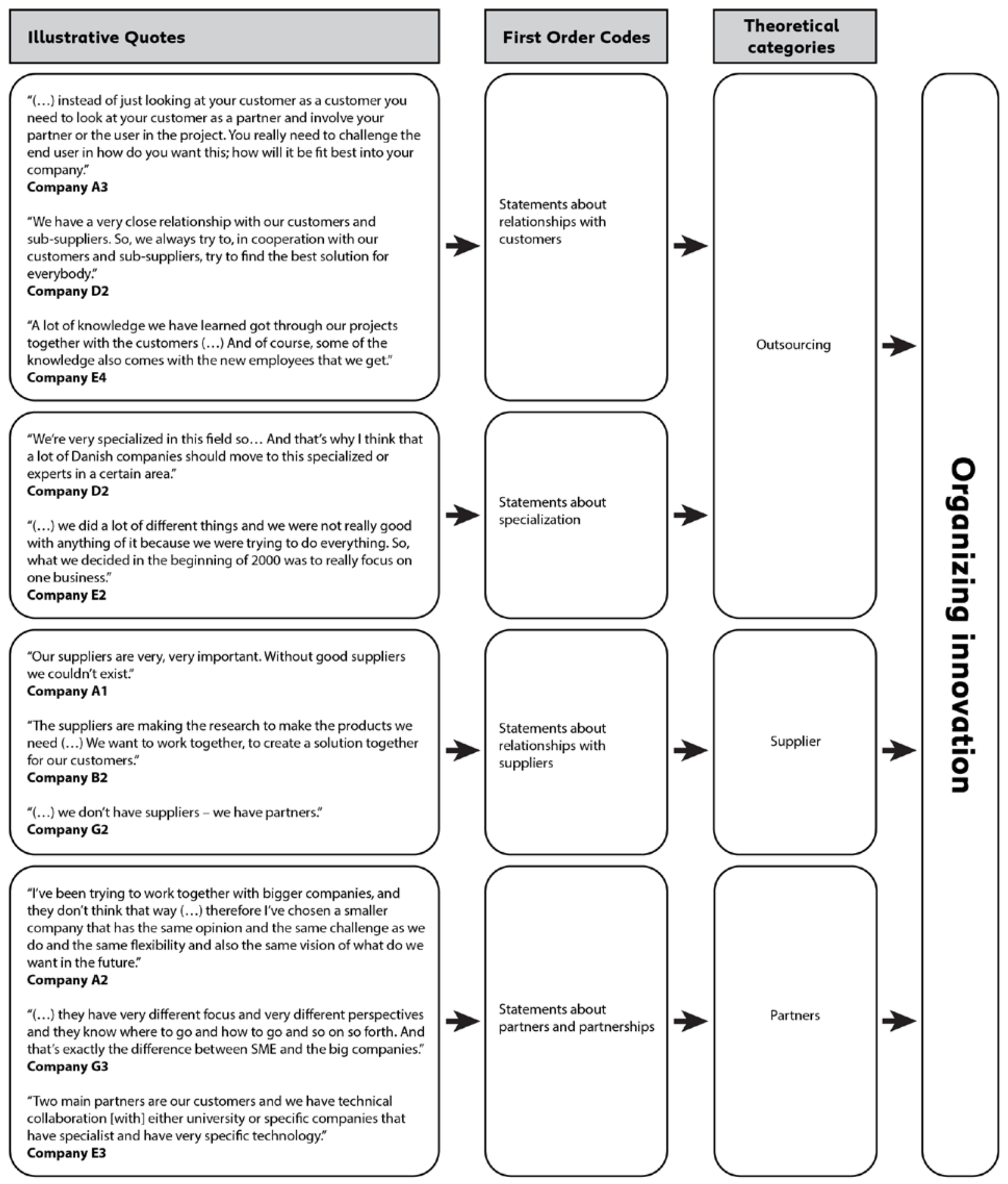




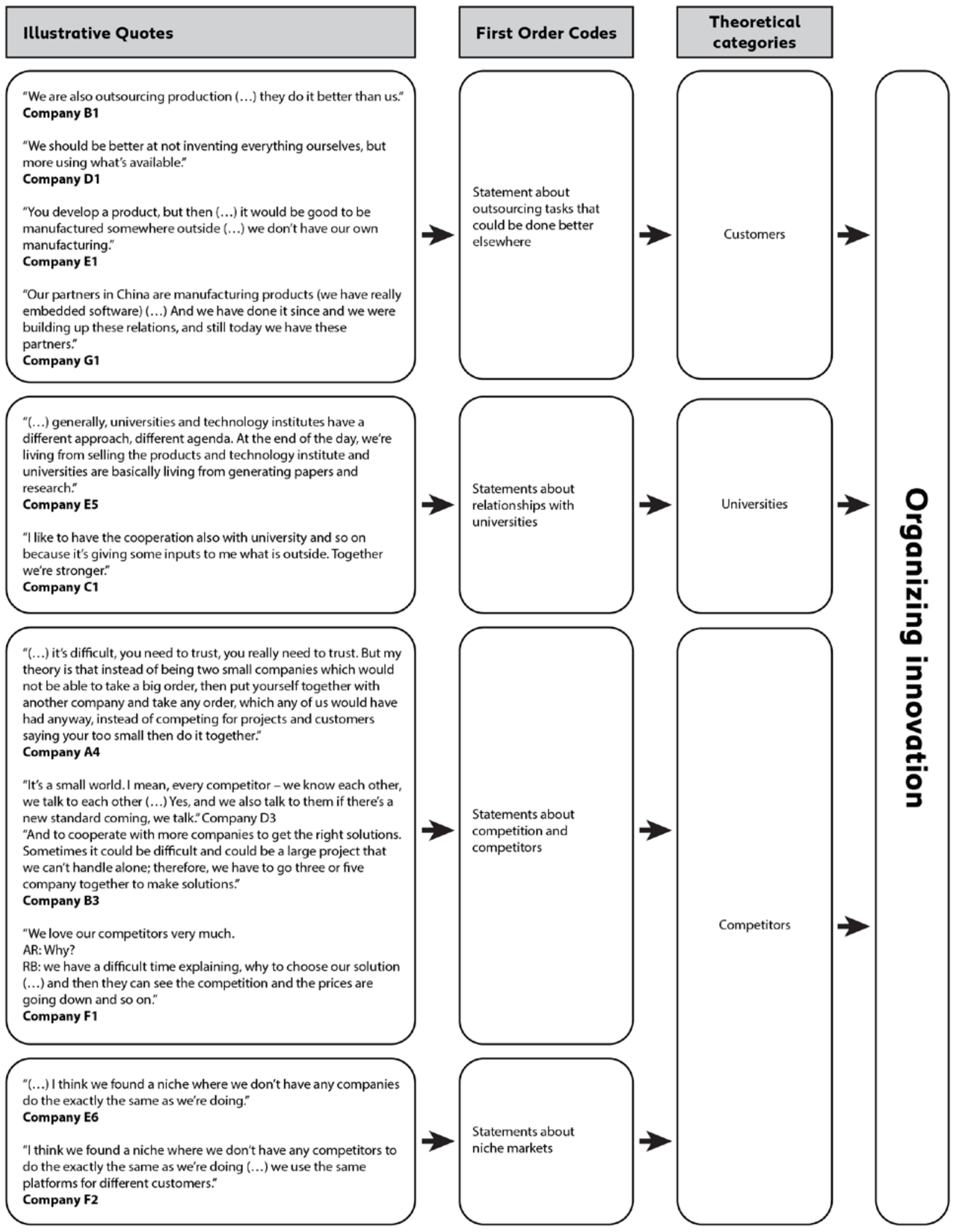


Table 5

Managing innovation coding scheme

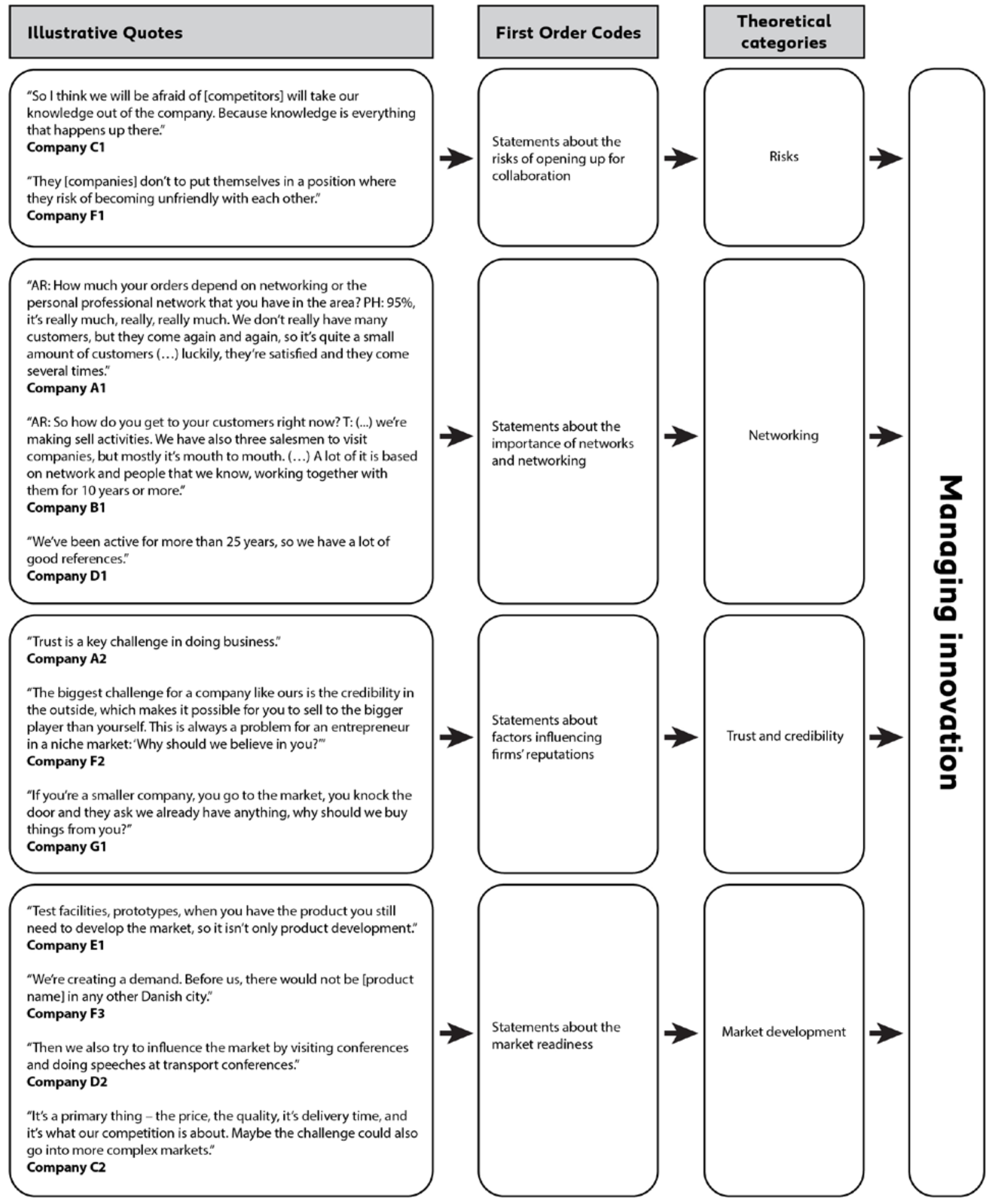

